LAWRENCE LIVERMORE N A TIO N A L LABORATORY
Changes in Perforation-Induced Formation Damage With Degree of Underbalance: Comparison of Sandstone and Limestone Formations

P. M. Halleck, C. O. Karacan, J. Hardesty, R. Detwiler

October 23, 2003

SPE International Symposium and Exhibition on Formation Damage Control

Lafayette, LA, United States

February 18, 2004 through February 20, 2004 
This document was prepared as an account of work sponsored by an agency of the United States Government. Neither the United States Government nor the University of California nor any of their employees, makes any warranty, express or implied, or assumes any legal liability or responsibility for the accuracy, completeness, or usefulness of any information, apparatus, product, or process disclosed, or represents that its use would not infringe privately owned rights. Reference herein to any specific commercial product, process, or service by trade name, trademark, manufacturer, or otherwise, does not necessarily constitute or imply its endorsement, recommendation, or favoring by the United States Government or the University of California. The views and opinions of authors expressed herein do not necessarily state or reflect those of the United States Government or the University of California, and shall not be used for advertising or product endorsement purposes. 


\section{Changes in Perforation-Induced Formation Damage With Degree of Underbalance: Comparison of Sandstone and Limestone Formations}

Phillip M. Halleck, SPE, and C. Ozgen Karacan, SPE, The Pennsylvania State University; John Hardesty, SPE, Jet

Research Center; Russ Detwiler, SPE, Lawrence Livermore National Laboratory

\section{Abstract}

Field data and recently developed models provide some guidance for estimating the underbalance needed to obtain fully functional perforations, but there are little data available that relate flow efficiency to lower underbalances in different rock types. To improve understanding of the surge cleanup process, we have performed two series of perforation flow tests in Berea Sandstone and in Bedford Limestone cores at increasing levels of underbalance. Flow tests were performed according to modified API RP43, section 4 test procedures. At the conclusion of the tests, the cores were analyzed using high-resolution X-ray CT techniques. The shape, dimensions and total volumes of both the open tunnel and the remaining embedded liner metal were extracted from the CT data and correlated with the underbalance and with the flow test results.

Open tunnel diameters and volumes are much lower in the limestone samples. While the amount of metal remaining in the tunnel and at the perforation tip decreases dramatically with underbalance in Berea Sandstone cores, the amount of metal is nearly constant in the limestone cores. Conversely, the tunnel volume increases with underbalance in the Sandstone cores but stays constant in the limestone. Core flow efficiency results correlate with these observations. There is a sharp increase in CFE in the sandstone samples as the tunnel volumes increase and little change in CFE in the limestone samples corresponding to unchanging tunnel volume.

The tests also offer some evidence of the cleanup mechanism at the perforation tip, at least in the sandstone cores. Samples at intermediate underbalance levels show evidence of open tunnel space in an annulus surrounding the metal slug at the tip. This suggests that cleanup may proceed at least partially by axial flow through crushed rock surrounding the metal. As this material erodes away, the metal is loosened and is flushed from the tunnel. Existing models for cleanup are based primarily on radial flow.

\section{Background}

Underbalanced perforating continues to be the technique most commonly used to prevent and remove permeability damage from perforation tunnels. While generally successful in improving the quality of perforated completions, much remains to be understood in predicting the underbalance pressure required in a specific situation and in predicting the flow performance of a given completion.

Significant progress has been made recently in developing models that can predict the extent of perforation cleanup for a given formation permeability and underbalance pressure (Tariq, 1990; Behrmann, 1995; Detwiler et al., 2003). These models calculate transient radial flow into an empty perforation tunnel and are based on the principle that some minimum Darcy-flow velocity is needed to remove fines from the rock surrounding the tunnel. Experimental studies have been able to map the permeability around the tunnel and to correlate it with reduced particle size distribution near the tunnel wall (Rochon et al., 1995; Karacan et al., 2000).

However, little attention as been paid to the mechanism by which rock and charge debris are removed from the tunnel in order to achieve an open tunnel in the first place. This necessarily requires substantial flow along the tunnel in addition to the radial flow postulated by current models. Sufficient underbalance is known to remove even the metal slug at the perforation tip and it is difficult to imagine this being accomplished purely by radial flow.

\section{Objective and Approach}

Our objectives were simply to gain better insight into the mechanisms by which under-balance surge removes damaged rock and charge debris from a perforation and to better characterize the damaging materials left behind. Recognizing that dynamic failure occurs in different ways in different mineralogies, we also sought to distinguish between behavior in sandstones and limestones. To reach these objectives we have performed a series of perforation flow experiments in two different rocks at successively higher underbalance conditions. Following conventional flow testing of the perforated samples, we applied high-resolution X-ray CT analysis to observe the extent, geometry and morphology of debris remaining in the perforation tunnel.

\section{Methods}

We chose Berea Sandstone and Bedford (Indiana) Limestone for testing, based on extensive experience and availability of literature data on their properties and behavior. Perforation flow tests were performed according to slightly modified procedures given in API RP43, section 4 (1991). The cores used were 18-cm (7-in) in diameter and 46-cm (18in) long, with the core axis perpendicular to the sedimentary bedding planes. All cores were saturated with odorless mineral spirits with no water phase present. Permeability measurements were performed prior to perforating, both along the sample axis and across its diameter. These data were subsequently used in combination with observed penetration data and post-shot flow data to calculate core flow efficiency (CFE) values for each underbalance condition. For all of these tests, the shot was conducted with a constant radial pressure boundary condition. These conditions tend to simulate lowshot density situations with little or no wellbore damage (Deo et al., 1989.) The specific protocol followed was:

1. Sample was built into pre-shot measurement fixture.

2. The sample was taken to test-pressure conditions. 
3. The flow rate in the axial production direction was measured in a progression of induced pressure drops from 0.34 to $2.40 \mathrm{MPa}$ (50 psi to $350 \mathrm{psi}$ ).

4. The direction of flow was reversed, and the axial flow rate measurement was repeated.

5. Flow was switched to the cross-diameter distributors, and the flow rate parallel to the bedding planes was measured as a function of the same pressure drops.

6 . The target was removed from the chamber, and the axial flow sleeve was replaced with the radial flow sleeve. A 0.25 " diameter restriction plate was placed on top of the core, and restricted flow was measured with the constant radial pressure boundary condition.

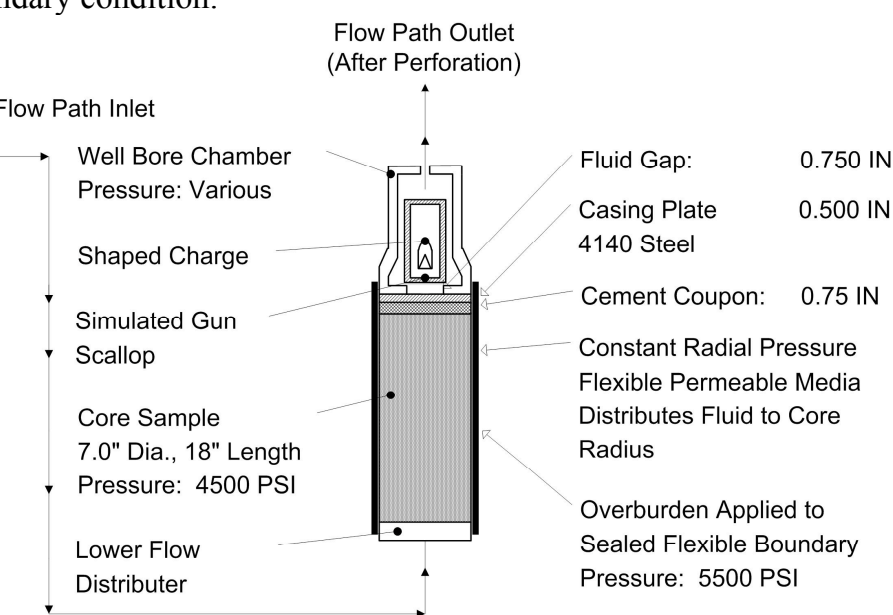

Figure 1: Configuration for perforating and post-shot flow testing

7. The fixture was removed from the overburden chamber, and rebuilt to shot configuration Figure 1.) The restriction plate was removed, and the upper distributor replaced with the wellbore chamber and the casing and cement coupon through which the shot is fired. The top end and curved surfaces of the sample were sealed, and pressure and flow were supplied from the lower end of the sample.

8. The specified pressure conditions were applied to the sample.

9. The perforation charge was detonated. The wellbore and pore pressures were allowed to equalize.

10. The pressure was reduced on the outlet side (top) of the sample, to induce flow in the production direction.

11. Flow rate was measured as a function of varied pressure drop.

12. The direction of flow was reversed, and the injection flow rate was measured as a function of pressure drop across the length of the core.

13. The fixture was removed from the chamber, and disassembled. The debris from the gun, wellbore, and perforation were collected and preserved.

Following perforating and flow testing, the cores were analyzed using high-resolution X-ray CT analysis using our Universal Systems HD600 industrial scanner (Figure 2). This unique device has two X-ray sources for micro and macro samples, an adjustable magnification axis for maximum sample resolution, and an area detector for volume scanning. The cores were air dried, then mounted in open air in the scanner. We used a Pantak X-ray source operating at $290 \mathrm{kV}$ and $4.5 \mathrm{~mA}$ with the sample axis $750 \mathrm{~mm}$ from the source.

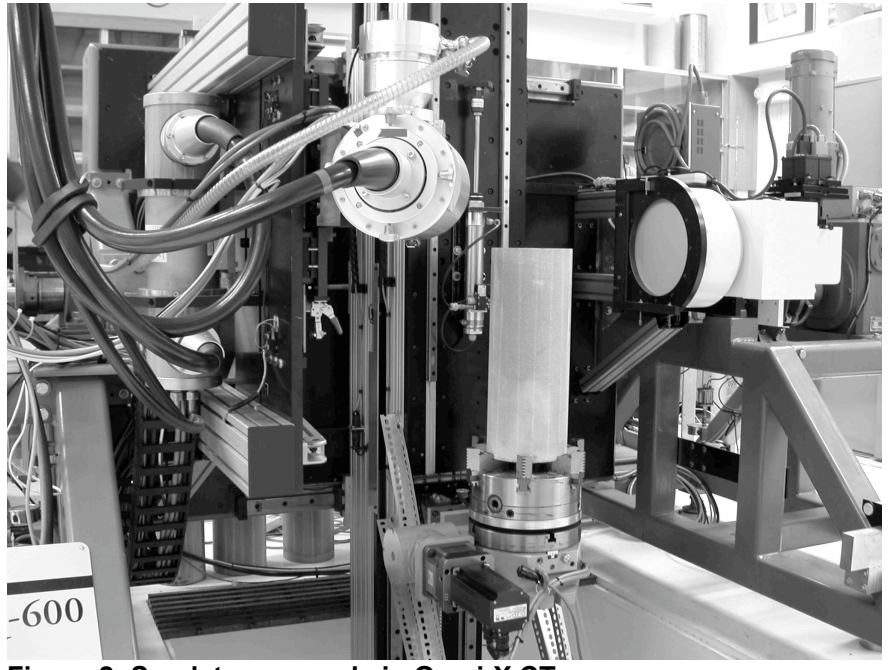

Figure 2: Sandstone sample in Omni-X CT scanner

We collected data from fifty lines of detectors, reconstructing five slices at a time. With the detector 1090 $\mathrm{mm}$ from the source, this arrangement results in full 3-D coverage of the inner $2 / 3$ of the sample with slices approximately $0.7 \mathrm{~mm}$ thick and with cross-section pixel size of $0.25 \times 0.25 \mathrm{~mm}$.

The resulting data were displayed in three dimensions using combinations of three public domain and commercial software packages. These allow extraction of distinguishable features within sample, such as the metal and open tunnel, for display in 3-D perspective. We also wrote routines in the Wave computer language to calculate the respective volumes of metal and tunnel as described below.

\section{Results and Observations Sandstone tests}

CFE values, calculated as described above are tabulated versus the applied underbalance in Table 1. Also reported are the volumes of the metal and open tunnel as discussed below. Two values of penetration depth are reported-one from probing the sample and a second from X-ray CT observation of the deepest metal. While generally consistent, there are some instances in which the probe depth is actually deeper

\begin{tabular}{|c|c|c|c|c|c|}
\hline $\begin{array}{c}\text { UB } \\
\text { pressure } \\
(\mathrm{MPa})\end{array}$ & CFE & $\begin{array}{c}\text { Tunnel } \\
\text { Vol. } \\
\left(\mathrm{cm}^{3}\right)\end{array}$ & $\begin{array}{c}\text { Metal } \\
\text { Vol. } \\
\left(\mathrm{cm}^{3}\right)\end{array}$ & $\begin{array}{c}\text { Probe } \\
\text { Penet. }(\mathrm{cm})\end{array}$ & $\begin{array}{c}\text { Penet. From } \\
\text { CT data }(\mathrm{cm})\end{array}$ \\
\hline 5.2 & 0.91 & 10.5 & 2.6 & 12.6 & 12.2 \\
\hline 6.9 & 0.79 & 14.0 & 0.4 & 15.4 & 16.2 \\
\hline 10.3 & 0.62 & 10.7 & 2.8 & 15.7 & 15.2 \\
\hline 13.8 & 0.82 & 10.3 & 1.6 & 14.7 & 16.1 \\
\hline 17.2 & 0.94 & 13.4 & 0.7 & 9.7 & 8.1 \\
\hline 20.7 & 1.25 & 13.6 & 0.5 & 10.6 & 9.6 \\
\hline
\end{tabular}

Table 1: Flow, tunnel volume and metal volumes for tests in Berea Sandstone

than the deepest metal. We suggest that the stiff probe pushes through weakened rock beyond the metal tip in these cases. For current purposes, we used probe penetration depths to calculate the CFE values.

The data are not entirely as expected since there is an initial decrease in CFE with increasing underbalance pressure. 
with the lowest $\mathrm{CFE}$ at 10.3-MPa (1500-psi) underbalance. CFE increases at higher underbalances as expected, culminating in an unrealistic value greater than one at an underbalance of $20.7 \mathrm{MPa}$ (3000 psi.)

Figure 3 shows X-ray CT results from this test series with underbalance increasing downward. For each perforation the figure shows open tunnel section (in dark gray) and a metal "slug" remaining at the tip (shown in light gray). There is a very small gap between the tunnel section and the metal representing a tunnel section that is filled with rock debris. This volume is not represented in the figure because it is indistinguishable from the surrounding rock, which has been removed by the software. As expected, the overall trend is for increasing open tunnel volumes and decreasing metal volumes as underbalance increases. For reasons probably unrelated to underbalance the last two penetrations are uncharacteristically short.

Note that there is some evidence of open-hole volume around the outside of the metal slug at both 5.2-and 10.3-MPa (750- and 1500-psi) underbalance conditions (first and third perforations in the figure). This phenomenon is shown more clearly in Figure 4 of the test at 5.2-MPa (750-psi) underbalance. Here, an annulus wraps halfway around the metal slug. We believe, as discussed below, that this represents a new observation revealing part of the mechanism by which underbalance surge flow cleans perforation tunnels.

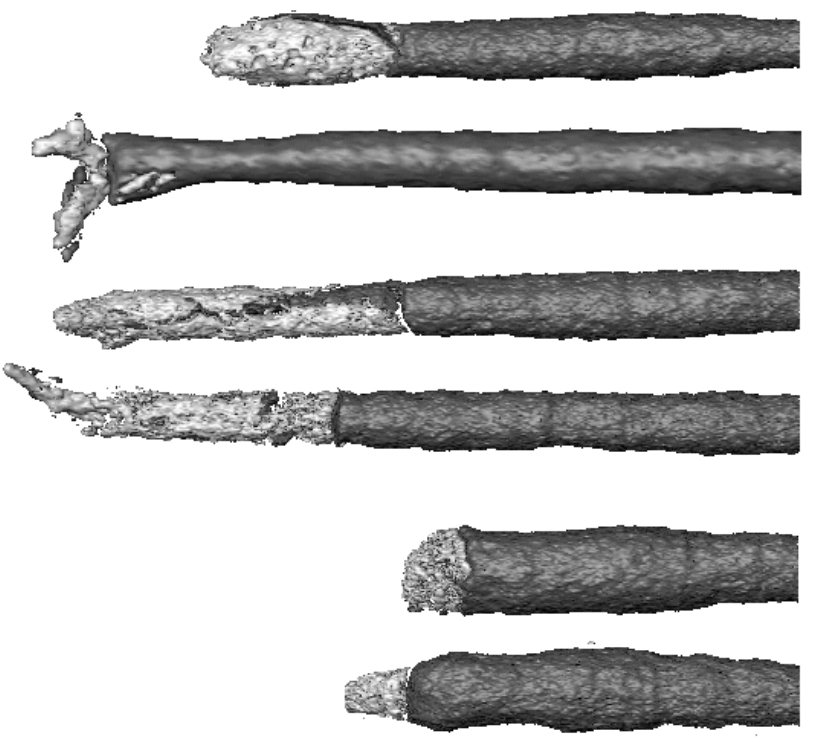

Figure 3: Tunnel (dark gray) and metal (light gray) volumes at increasing underbalance in sandstone.

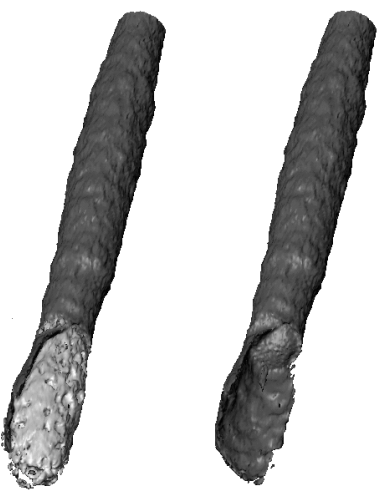

Figure 4: Close-up of tunnel and metal volumes (left) at 5.2-MPa (750-psi) underbalance, and the open annulus around the metal slug (right, metal removed).

Figure 5 is a cross section image through the metal slug itself. This clearly shows the annular volume at the bottom. The variation in color of the metal slug shows that the density of the metal is not uniform. While there are areas of solid metal, much of it is mixed with rock and charge debris, reducing its $\mathrm{x}$-ray opacity. The quantitative metal volumes tabulated later in the paper should be interpreted with this in mind.

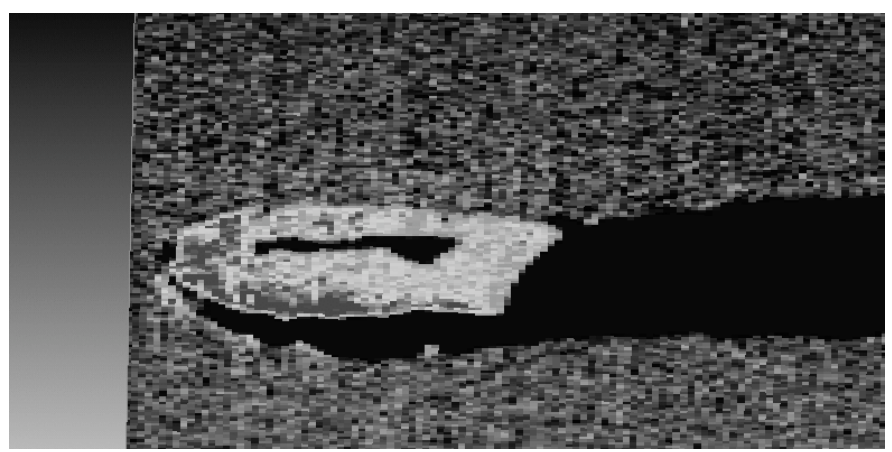

Figure 5: Cross section of metal slug at 5.2-MPa (750-psi) underbalance showing annulus and variation in metal density.

From the CT data it is possible to extract the volumes of the metal and the open tunnel quantitatively. Each X-ray CT image is really a 2-D array of X-ray absorption values (termed CT numbers) that are turned into a visual image simply by assigning a color or grayscale mapping to those numbers. The stack of adjacent images is thus a 3-D array of such numbers, which we can examine quantitatively. Knowing the volume of space, or voxel, represented by each number, we can obtain the total volume of metal by simply finding and adding all voxels with X-ray absorptions corresponding to the metal. In fact figures 3 and 4 are just perspective views of volumes extracted in this way.

Since the absorption of the metal is greater than that of the rock, extracting the metal volume is a matter of selecting a threshold CT number. Any voxel with a CT number above this threshold is considered to be metal. This is why the variable density of the metal slug, presumably due to mixing of metal particles with rock and charge debris, makes setting the threshold somewhat arbitrary. For this study we chose the threshold by gradually increasing it until there was little additional change in the resulting metal volume. The same was done for the threshold between open tunnel and rock. The 
results for these calculations are tabulated, along with CFE and underbalance pressure values in Table 1 above.

There is a fairly clear trend towards decreasing metal volume with increasing underbalance. Increase in tunnel volume is not as clear. The two shorter penetrations at higher underbalance tend to mask this effect in the data.

\section{Tests in Bedford Limestone}

Similar test data for tests in limestone samples are tabulated in table 2. CFE values are much reduced compared to those in the higher-permeability sandstone samples as expected. Further, underbalance pressures up to $20.7 \mathrm{MPa}$ (3000 psi) do not have a significant effect on flow performance. At the same time, there is no significant trend in either tunnel or metal volume with underbalance. Both metal and tunnel volumes are significantly smaller than for Berea Sandstone tests, despite penetration depths that are generally larger.

The morphology of the perforations, particularly the metal at the perforation tip, is completely different in these tests than in the sandstone tests. Figure 6 is a plate of perforations from this test series, again shown with increasing underbalance. The open-tunnel portion extends about $40 \%$ of the perforation length. The metal at the tip is distributed in multiple small fractures, resulting in flower-shaped slug. There is no evidence of annular space around any of the metal.

\begin{tabular}{|c|c|c|c|c|c|}
\hline $\begin{array}{c}\text { UB } \\
\text { pressure } \\
(\mathrm{MPa})\end{array}$ & CFE & $\begin{array}{c}\text { Tunnel } \\
\text { Vol. } \\
\left(\mathrm{cm}^{3}\right)\end{array}$ & $\begin{array}{c}\text { Metal } \\
\text { Vol. } \\
\left(\mathrm{cm}^{3}\right)\end{array}$ & $\begin{array}{c}\text { Probe } \\
\text { Penet. } \\
(\mathrm{cm})\end{array}$ & $\begin{array}{c}\text { Penet. from } \\
\text { CT data } \\
(\mathrm{cm})\end{array}$ \\
\hline 5.2 & 0.25 & 1.60 & 1.08 & 12.6 & 21.4 \\
\hline 6.9 & 0.35 & 1.64 & 1.13 & 15.4 & 21.4 \\
\hline 10.3 & 0.35 & 1.10 & 1.46 & 15.7 & 22.6 \\
\hline 13.8 & 0.26 & 1.00 & 1.47 & 14.7 & 20.1 \\
\hline 17.2 & 0.28 & 1.04 & 1.79 & 9.7 & 23.6 \\
\hline 20.7 & 0.23 & 1.59 & 1.50 & 10.6 & 21.2 \\
\hline
\end{tabular}

Table 2: Flow, tunnel volume and metal volumes for tests in Bedford Limestone

There is a large gap between the open-tunnel portion of the perforation and the metal at its tip. This invisible region represents tunnel filled with rock debris that is indistinguishable (using the selected CT number thresholds) from the surrounding rock.

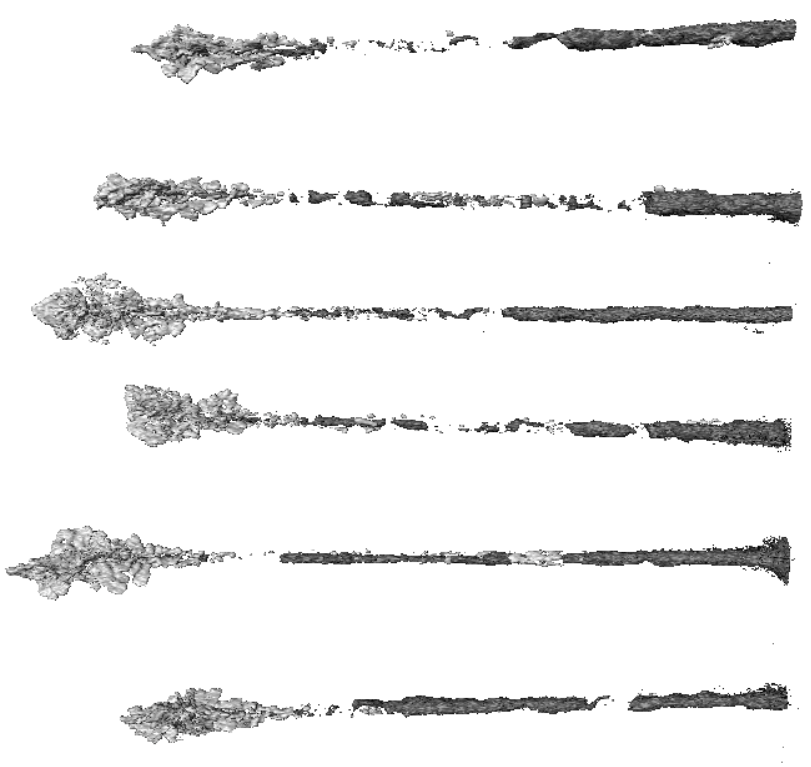

Figure 6: Perforation tunnel (dark gray) and metal (light gray) volumes at increasing underbalance in Bedford Limestone

Figure 7 is a perspective view of the open tunnel and metal volumes at 20.7-MPa (3000-psi) underbalance. The left image shows both metal and tunnel viewed from the tip of the perforation. The right image shows the metal removed. There is a small open volume in the heart of the metal slug, but no indication of tunnel development around the outside of the metal as was observed in the sandstone samples.

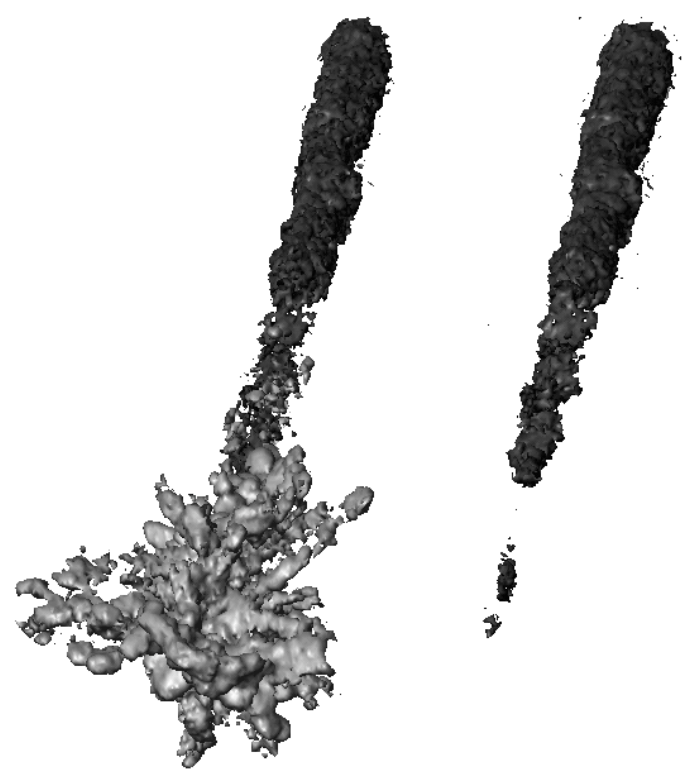

Figure 7: Perforation tunnel and metal at 20.7-MPa (3000-psi) underbalance in limestone

\section{Discussion}


Recent models of perforation cleanup concentrate on transient radial flow into an open tunnel. It is thought that if surge flow velocity is sufficiently high (based on either onset of "turbulence" or on some drag-force criterion) that fine plugging particles are swept from the rock surrounding the tunnel. These models are consistent with both field and laboratory observations showing that higher underbalances are needed with lower permeability formations. However, they beg the issue of how the open tunnel is initially formed.

The X-ray CT results for sandstone illustrate that an annular space develops around the solid metal at the perforation tip. This in turn has two implications. First, there must be an axial component to the surge flow around the outside of the metal slug. Second, this in turn implies that there is a zone of weakened rock surrounding the metal. Emptying the tunnel in front of the metal slug, causing a high axial pressure gradient at the tip, can cause axial flow.

In order for this flow to create an annulus, the rock through which it flows must be weakened relative to the surrounding rock. Previously reported maps of rock strength adjacent to a perforation (Halleck et al., 1995) support this supposition. The data were obtained using a modified indentation hardness tester. They show a progressive weakening of the rock in sandstone samples as the wall of the perforation tunnel is approached.

We propose that cleanup of debris in the tunnel, and in particular of the metal at the perforation tip, proceeds by axial surge flow that loosens the material so that it can be subsequently flushed from the tunnel. Further cleanup of permeability damage in the rock surrounding the tunnel then proceeds by radial inward flow, progressing towards the perforation tip as the tunnel itself is cleaned. The sequence of the interaction between axial surge flow around and through the tunnel debris and radial flow though damaged rock surrounding the tunnel will depend on local permeability variations, fluid compressibility and viscosity and on strengths of the native and damaged rock and of the rock and charge debris.

Behavior in the limestone samples is different than in the sandstone in several respects. First, as expected from its relatively low permeability, underbalances in the range tested have little effect on CFE or metal volume and only a small effect on tunnel volume. The fact that there is no annular open space around the metal suggests that either there is insufficient axial flow to remove the adjacent rock or that the rock is not weakened enough to be removed by the flow available. Surge flow velocities in general must be lower in the limestone because of its lower permeability. In addition, calcite is known to fail plastically under shock conditions so that the basic failure mechanism in limestone is by flow of the calcite crystals. Failure of quartz is by grain breakage (cataclasis), resulting in more disaggregated and weaker failure products.

The effect of these differences means that there is insufficient flow in the tunnel to remove all the rock debris and insufficient flow around the metal to loosen it. The large surface area of the complex-shaped slug in limestone samples further decreases local flow velocity.

Two additional observations deserve discussion. The first is that probe and CT-based penetrations in the sandstone samples appear inconsistent. Probe penetration is measured by inserting a stiff metal probe into the perforation until in encounters hard material, presumed to be either compacted metal or undamaged rock. In some cases, Table 1 shows that probe depths are actually greater than the depth of the metal measured using CT data. We believe that this is due to the nature of the damaged rock around the metal and to the distribution of the metal itself.

We have already noted the weakened rock around the perforation and specifically around the metal slug. This weakened material frequently extends beyond the perforation tip as well. A fortuitously placed stiff probe can be forced through weakened material beside the metal and on into weak rock beyond the tip. In limestone samples, the rock is not significantly weakened due to the nature of its failure and the metal itself is spread out in a complex pattern. This makes it much more difficult for a probe to pass the slug. Table 2 shows that probe depths in limestone samples are always significantly less than the CT-observed values.

Secondly, we take note of the anomalously low metal volume and high tunnel volume in the sandstone test at 6.9 -MPa (1000-psi) underbalance. This is a much cleaner perforation than tests succeeding tests at higher underbalances. Figure 3 also shows are badly deformed slug at its tip. We hypothesize that this badly formed jet tail allowed axial surge flow into the perforation, increasing flow along tunnel and resulting in better cleaning.

\section{Conclusions}

- Cleanup of metal debris in Berea Sandstone samples proceeds by first flushing weakened rock from around the slug, loosening it.

- Tunnel volumes increase and metal volumes decrease with increasing underbalance in sandstones. However there is only a poor correlation between these volumes and the measured CFE.

- Metal slug geometry in Bedford Limestone is very different than in Berea Sandstones. The metal is dispersed in many small fractures and is not easily removed by surge flow.

- Even large underbalance conditions fail to increase open tunnel volume or reduce metal volume in Bedford limestone due to low permeability and complex slug geometry.

\section{Acknowledgements}

This work was performed under the auspices of the U. S. Department of Energy by the University of California, Lawrence Livermore National Laboratory under Contract No.W-7405-Eng-48. The authors thank the management of Halliburton Energy Services, Inc. and Jet Research Center for permission to publish this paper. 


\section{References}

American Petroleum Institute, Recommended Practices for Evaluation of Well Perforators (RP43) fifth edition, January 1991, Publications and Distributions Sections, 1220 L Street NW, Washington, D.C. 20005, Order No. 811-08600

Behrmann, L.A.: "Underbalance Criteria for Minimum Perforation Damage," SPE paper 30081 presented at the 1995 SPE Formation Damage Symposium, 21-29. SPE Drilling and Completions (Sept. 1996) 73.

Deo, M., S. Tariq, and P. M. Halleck, 1989, "Linear and Radial Flow Targets for Characterizing Down-hole Flow in Perforations", SPE paper 16896, SPE Prod. Engr., p. 295-300.

Detwiler, R.L., Morris, J.P., Karacan, C.O., Halleck, P.M., and Hardesty, J.: "Evaluation of the Relative Importance of Parameters Influencing Perforation Cleanup", SPE paper 86538 presented at the 2003 SPE Formation Damage Symposium, Lafayette, LA, Feb. $18-20$.

Halleck, P.M., Poyol, E. and Santarelli, F. J.: "Estimating Perforation Flow Performance From Variation in Indentation Hardness", SPE Drilling and Completion, 271, Dec. 1995.

Karacan C. O., Grader A. S, and Halleck, P. M.: "Mapping of Permeability Damage Around Perforation Tunnels", paper ETCE2000/PROD-10036, ASME, ETCE/OMAE2000 Joint Conference, New Orleans, LA, Feb. 14-17, 2000.

Rochon, J., Creusot, M., Feugas, D., Thibeau, S. and Bergerot, J-L.: "Viscous Fluids Characterize the Crushed Zone," SPE Drilling and Completion, pp 198-203, September 1995.

Tariq, S.M.: "New, Generalized Criteria For Determining the Level of Underbalance for Obtaining Clean Perforations," paper SPE 20636 presented at the 1990 SPE Annual Technical Conference and Exhibition, New Orleans, LA, Sept. 23-26.

\section{Metric Conversions}

$1 \mathrm{~cm}=0.394$ in

$1 \mathrm{MPa}=145.0 \mathrm{psi}$ 